\title{
Pregnancy Outcomes in Maternal Neuropsychiatric Illness and Substance Abuse
}

\section{Untersuchung zum Schwangerschaftsausgang bei maternaler neuropsychiatrischer Erkrankung oder stoffgebundener Suchterkrankung}

Authors

Severine Bartel ${ }^{1}$, Serban Dan Costa ${ }^{2}$, Siegfried Kropf ${ }^{3}$, Anke Redlich ${ }^{2}$, Anke Rissmann ${ }^{1}$

Affiliations

1 Fehlbildungsmonitoring Sachsen-Anhalt, Medizinische Fakultät der Otto-von-Guericke Universität Magdeburg, Magdeburg, Germany

2 Universitätsfrauenklinik Magdeburg, Medizinische Fakultät der Otto-von-Guericke Universität Magdeburg, Magdeburg, Germany

3 Institut für Biometrie und Medizinische Informatik (IBMI), Medizinische Fakultät der Otto-von-Guericke Universität Magdeburg, Magdeburg, Germany

Key words pregnancy outcome, neuropsychiatric illness, abortion, fetal outcome, pregnancy

Schlüsselwörter

Schwangerschaftsausgang, neuropsychiatrische Erkrankung, Abort, fetales Outcome, Schwangerschaft

received 7.9.2017

revised 27.9.2017

accepted 9.10.2017

Bibliography

DOI https://doi.org/10.1055/s-0043-120920

Geburtsh Frauenheilk 2017; 77: 1189-1199 @ Georg Thieme

Verlag KG Stuttgart · New York | ISSN 0016-5751

Correspondence

Anke Rissmann

Fehlbildungsmonitoring Sachsen-Anhalt, Medizinische

Fakultät der Otto-von-Guericke-Universität Magdeburg Leipziger Straße 44, 39120 Magdeburg, Germany

anke.rissmann@med.ovgu.de

Deutsche Version unter:

https://doi.org/10.1055/s-0043-120920

\section{ABSTRACT}

Introduction Worldwide the prevalence of neuropsychiatric illness among women of reproductive age is higher than ever before. This study investigates the influences of maternal substance abuse/dependence and neuropsychiatric illness on pregnancy and neonatal outcomes.

Patients and Methods Using a retrospective study design 185 pregnancies in women with neuropsychiatric illnesses or substance abuse were identified at a single centre over a period of 3.25 years and compared to 4907 pregnancies in healthy women without mental illness. Differences in pre-, peri- and postnatal pregnancy parameters were studied.

Results Numbers of previous abortions on obstetric history were significantly higher in cases compared to controls, women with depression being especially affected. The number of antenatal visits was also higher among cases, especially in women with depression. The caesarean section rate was significantly higher in cases compared to controls. Children of women with neuropsychiatric illness were born at lower gestational ages than those of healthy control mothers, however there were no significant differences between case and control groups for birth weight, head circumference or Apgar scores. Some isolated differences were found for disease-specific case subgroups compared to controls.

Conclusion The study shows a relationship between maternal neuropsychiatric illness and pregnancy outcomes independent of medication use. Rates of spontaneous abortion were higher. Children were born earlier, yet the neonatal outcomes birth weight, head circumference and Apgar score were not worse than children of mentally healthy women.

\section{ZUSAMMENFASSUNG}

Einleitung Unter Frauen im gebärfähigen Alter ist die Prävalenz neuropsychiatrischer Erkrankungen weltweit so hoch wie nie. Die Studie geht der Frage nach, welchen Einfluss die mütterliche Suchterkrankung oder neuropsychiatrische Erkrankung auf den Schwangerschaftsausgang und auf das neonatale Outcome hat.

Patienten und Methoden In einer monozentrischen, retrospektiven Studie konnten über einen Zeitraum von 3,25 Jah- 
ren 185 Schwangerschaften von Frauen mit neuropsychiatrischer Erkrankung oder Suchterkrankung identifiziert werden und 4907 Schwangerschaften von mental gesunden Frauen gegenübergestellt werden. Es wurden Unterschiede im prä-, peri- und postpartalen Schwangerschaftsverlauf untersucht.

Ergebnisse Die Anzahl an anamnestischen Aborten war in der Fallgruppe signifikant höher als in der Kontrollgruppe. Vor allem Frauen mit Depression waren davon betroffen. Auch die Anzahl an Vorsorgeuntersuchungen während der Schwangerschaft war in der Fallgruppe vor allem durch Frauen mit Depression erhöht. Die Sectiorate der Fallgruppe war gegenüber der Kontrollgruppe signifikant erhöht. Die Kinder neuropsychiatrisch erkrankter Frauen sind früher zur Welt gekommen als Kinder der Kontrollmütter. Sie hatten jedoch im
Vergleich von Fall- und Kontrollgruppe kein signifikant niedrigeres Geburtsgewicht, keinen kleineren Kopfumfang oder schlechtere APGAR-Werte. Im Vergleich einzelner krankheitsspezifischer Untergruppen zur Kontrollgruppe lagen vereinzelt Unterschiede vor.

Fazit Es konnte ein Zusammenhang zwischen neuropsychiatrischer Erkrankung der Mutter und dem Schwangerschaftsausgang, unabhängig von der Medikation, nachgewiesen werden. Die Rate an Spontanaborten war höher. Die Kinder kamen früher zur Welt, jedoch war das Outcome der Kinder in Bezug auf Geburtsgewicht, Kopfumfang und APGAR-Werten nicht wesentlich schlechter als das von Kindern neuropsychiatrisch gesunder Frauen.

\section{Introduction}

The care of women expecting a child is the central focus of routine obstetric practice; optimal antenatal care is the primary goal. In order to achieve this, however, in addition to the pregnancy itself other potential somatic and psychiatric illnesses must be taken into consideration. Neuropsychiatric illnesses in particular are on the increase among women of reproductive age worldwide [1]. In 2013 the prevalence of depression among German women was estimated at $11.8 \%$ between $18-29$ years of age, $10.5 \%$ between $30-39$ years and $9.9 \%$ from 40 to 49 years of age. The lifetime prevalence of depression in German women is as high as $15.4 \%$ [2]. According to the WHO's “Global Burden of Disease" study, by 2020 unipolar depression will be the second most common cause of illness (after ischaemic heart disease) responsible for reduced quality-of-life [3]. A study from 2014 found that $27.7 \%$ of all Germans had suffered from at least one psychiatric problem in the previous 12 months (amongst others: anxiety disorders, depression, psychosis, addiction), young women being most affected [4].

An increasing proportion of women of reproductive age suffer from substance dependence/addiction [5]. According to a study by Gopman et al. in 2014, in New Mexico $10.7 \%$ of non-pregnant women/girls and $5.9 \%$ of pregnant women/girls between 15-44 years of age consumed illegal drugs [6].

Studies have proven the negative effects of drugs, alcohol and nicotine consumption during pregnancy on the unborn child [7].

Swedish studies show that rates of caesarean section, premature birth and low Apgar scores are higher among women with depression and use of antidepressants than in the general population $[8,9]$.

One Canadian study found an increased risk of prematurity and intrauterine growth restriction (small for gestational age, SGA) for children of mothers with schizophrenia [10].

However, apart from one study by Grunwald et al. there are no valid data available on pregnancy outcomes among mentally ill women in Germany [11]. The aim of this study was to describe the differences in pregnancy outcomes between women with neuropsychiatric illness or substance addiction (with and without medication) compared to mentally healthy women in a cohort from central Germany, and to define possible consequences for routine clinical practice.

\section{Patients and Methods}

\section{Patient collective, clinical parameters and data collection}

Data on 5092 pregnancies managed at a university women's hospital between 01.01.2010 and 31.03.2014 were analysed retrospectively. The study was authorised by the medical faculty ethics committee (113/14).

In this single centre, retrospective study we analysed data captured routinely for every birth using the local labour ward program (Nexus, PDM, Version 6.3.3.1), those captured by the hospital's internal information system (Medico, Version 23.00, Cerner HS Deutschland) and additional data taken from patient files. The parameters were collected in tabular form (Microsoft Excel 2010) and anonymised for the analysis. Patients were divided into a case group (CG) and a control group (CoG) according to ICD 10 codes for neuropsychiatric diagnoses that had been diagnosed by a specialist and stated by patients on hospital admission. Thus 185 case pregnancies, subsequently termed "cases", and 4907 control pregnancies, subsequently termed "controls" were identified for comparison. For the case group medical records, consent forms, $\mathrm{U} 1$ and U2 neonatal screening examination results and discharge summaries were studied for additional information. In the event of in-patient treatment information was expanded on using level 1 perinatal centre data. For some variables the case group was divided into specific subgroups according to neuropsychiatric diagnosis. - Fig. 1 provides an overview of the study population.

The following maternal parameters were analysed: Number of abortions on obstetric history, age during current pregnancy, number of antenatal visits during current pregnancy and mode of delivery.

The following neonatal parameters were analysed: interval to estimated date of delivery (EDD), birth weight, length and head circumference at birth and Apgar scores (after 1, 5 and 10 minutes). 


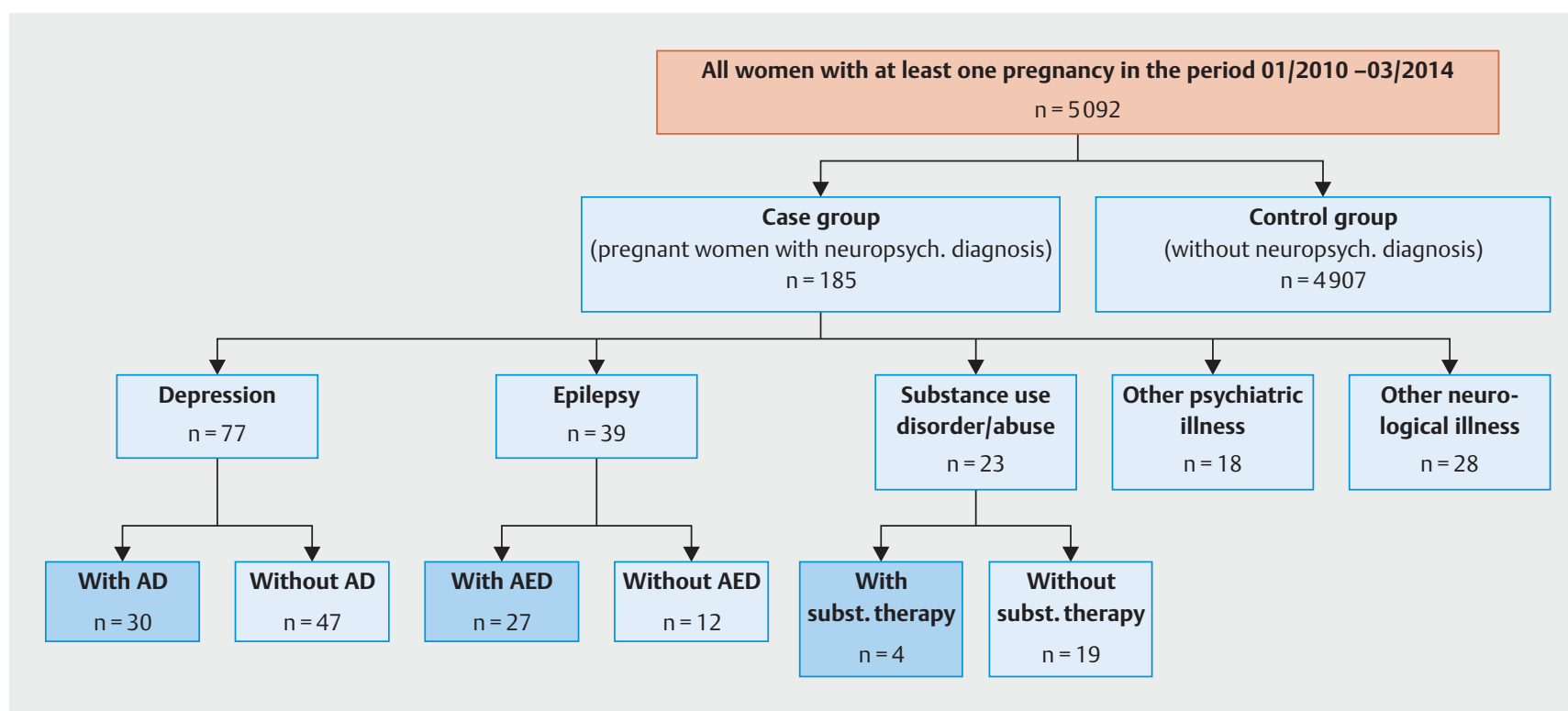

- Fig. 1 Flow diagram of study participants and division into subgroups. $A D=$ antidepressants, $A E D=$ anti-epileptic drugs, subst. = substitution therapy.

\section{Statistical analysis}

Statistical analysis was performed using the statistics software SAS, Version 9.4 (SAS Institute Inc., Cary, NC, USA). The sample was described using simple counting of events, cross tabulation including $x 2$ tests, calculation of means and standard deviations, and medians and quartiles represented in box plots.

Statistical comparison of maternal and neonatal characteristics was conducted at three levels. At the first level cases were only differentiated from controls. For the next level cases were subdivided according to the categories depression, epilepsy, substance abuse, other psychiatric illnesses and other neurological disorders. For more definite interpretability of results patients in the last two groups were then excluded from the analysis. At the third level the remaining three subgroups were further subdivided for use or non-use of disease-specific medications.

For the neonatal criteria birth weight, length and head circumference at birth and the three Apgar scores comparison between groups was made using covariant analysis (in SAS-Procedure PROC GLM) with sex and "twin yes/no" as factors in addition to group allocation, and "interval to EDD" as a covariable. At the second and third levels described above the Dunnett test was used to compare differences between the various case subgroups and the control group. Similar comparisons were performed for "interval to EDD", only that here the interval to EDD was no longer a covariable.

Maternal age between the groups was compared using a oneway analysis of variance and the above-stated group allocation (PROC GLM). The number of previous abortions and extrauterine pregnancies in the obstetric history, and the number of antenatal visits in the current pregnancy were compared between groups using a generalised linear model (PROC GLIMMIX) with age as a covariable. Here too in each case the Dunnett comparisons of the other groups were compared to the control group.
All tests were performed with an assumed error probability of $5 \%$. Adjustment for multiple tests was performed as described using the Dunnett procedure for comparison of groups. No further adjustments for analysis of the various parameters or grouping levels was performed.

\section{Results}

\section{Maternal collective}

\section{Case numbers}

The case group consisted of 169 pregnant women with neuropsychiatric diagnoses including 185 pregnancies with 193 live births. For comparison 4907 pregnancies with 5102 live born children served as controls. $3.6 \%$ of pregnancies were affected by maternal substance abuse or neuropsychiatric illness.

\section{Maternal neuropsychiatric illness}

- Table 1 shows the incidence distribution of neuropsychiatric diagnoses in the case group. Depression (including bipolar disorder and anxiety disorders), epilepsy, substance abuse, other psychiatric illnesses and other neurological disorders constitute the five largest groups numerically. The depression group, with an absolute incidence of 77 ( $41.6 \%$ of cases; $1.51 \%$ of the total collective), was the largest group overall followed by epilepsy with an absolute incidence of 39 ( $21.1 \%$ of cases; $0.77 \%$ of the total collective) and other neurological disorders with 28 (15.1\% of cases; $0.55 \%$ of the total collective). An additional 23 cases ( $12.5 \%$ of cases; $0.45 \%$ of the total collective) formed the group with substance abuse and 18 cases ( $9.7 \%$ of cases; $0.35 \%$ of the total collective) had other psychiatric illnesses. 
- Table 1 Incidence distribution of maternal neuropsychiatric diagnoses in the case group according to ICD 10 GM 2014.

\begin{tabular}{|c|c|c|c|}
\hline \multicolumn{2}{|c|}{ Maternal neuropsychiatric diagnoses according to ICD 10 (GM 2014) } & \multirow{2}{*}{$\begin{array}{l}\text { Absolute incidence } \\
(\mathrm{n}=185)\end{array}$} & \multirow{2}{*}{$\begin{array}{l}\text { Relative incidence } \\
\text { (\%) }\end{array}$} \\
\hline Main group & Subgroup & & \\
\hline I Depression (F31-F33) & $\begin{array}{l}\text { - Bipolar disorder and anxiety } \\
\text { disorders }(F 40,41,43)\end{array}$ & 77 & 41.6 \\
\hline II Epilepsy (G40) & & 39 & 21.1 \\
\hline III Substance abuse $(\mathrm{F} 10,11,19)$ & & 23 & 12.4 \\
\hline IV Other psychiatric illness $(\mathrm{F} 60,99,20,79,50)$ & & 18 & 9.7 \\
\hline \multirow[t]{5}{*}{ Of these: } & - Borderline personality disorder (F60) & 6 & 3.2 \\
\hline & - Unclassified mental illness (F99) & 3 & 1.6 \\
\hline & - Schizophrenia (F20) & 4 & 2.2 \\
\hline & - Mental retardation (F79) & 3 & 1.6 \\
\hline & - Anorexia nervosa (F50) & 2 & 1.1 \\
\hline $\begin{array}{l}\text { V Other neurological disorders } \\
(G 35,70,50,91,81,43,25,71,25)\end{array}$ & & 28 & 15.1 \\
\hline \multirow[t]{9}{*}{ Of these: } & - Multiple sclerosis (G35) & 12 & 6.5 \\
\hline & - Myasthenia gravis (G70) & 1 & 0.5 \\
\hline & - Trigeminal neuralgia (G50) & 1 & 0.5 \\
\hline & - Hydrocephalus (G91) & 3 & 1.6 \\
\hline & - Hemiparesis (G81) & 3 & 1.6 \\
\hline & - Migraine (G43) & 4 & 2.2 \\
\hline & - Restless legs syndrome (G25) & 2 & 1.1 \\
\hline & - Myotonic dystrophy (G71) & 1 & 0.5 \\
\hline & - Tremor (G25) & 1 & 0.5 \\
\hline
\end{tabular}

\section{Number of previous abortions}

Pregnant women in the case group had significantly more previous abortions on obstetric history than controls $(p=0.015)$.

Women with depression were the chief contributors to this significant difference $(p=0.001)$.

On more specific analysis a significantly higher number of previous abortions compared to controls was found among women with depression who were not taking antidepressants.

In contrast, women with depression who were taking antidepressants did not have significantly more previous abortions compared to controls.

- Table 2 gives a detailed overview of means, standard deviations and $p$ values.

\section{Age during current pregnancy}

- Table 2: There was no significant difference in average age of women between the case and control groups overall ( $p=0.543$ ).

Women in the case group with depression were significantly older than women in the control group ( $p=0.043)$.

Women in the case group with substance abuse were significantly younger on average than women in the control group $(p<0.001)$ and significance was particularly pronounced for those not on substitution therapy $(p<0.001)$.
Number of antenatal visits during current pregnancy

- Table 2: The number of antenatal visits during the current pregnancy was significantly higher for the case group compared to controls $(p=0.026)$. This significance was achieved by the groups of women with depression and those with antidepressant use in particular $(p<0.001)$.

\section{Mode of delivery}

- Table 3: Significantly more mothers in the case group had a primary classical caesarean section $(18.3 \%, p=0.015)$ than in the control group (11.9\%). Secondary caesareans and other forms of caesarean section were also significantly more frequent in the case group (CG) than in the control group (CoG) (secondary caesarean: CG 14.7\%; CoG 12.6\%; other caesarean sections: CG $11.0 \%$, CoG 7.9\%). The overall caesarean section rate in the case group was $44 \%$ compared to $32.4 \%$ in the control group. The most common mode of delivery in both groups was spontaneous vaginal delivery, with a higher frequency in the control group (CG 53.4\%; CoG 64,8\%).

\section{Neonatal collective}

Interval to estimated date of delivery (EDD)

- Fig. 2: Children of mothers in the case group were born significantly earlier on average than children of mothers in the control group $(p=0.003)$.

- Table 4 shows means, standard deviations and p values. 
- Table 2 Overview of maternal findings part 1.

\begin{tabular}{|c|c|c|c|c|c|c|}
\hline & & \multicolumn{2}{|c|}{ Case groups } & \multicolumn{2}{|c|}{ Control group } & \multirow{2}{*}{$\begin{array}{l}\text { Significance } \\
\text { (p value)* }\end{array}$} \\
\hline & & MW & SD & MW & SD & \\
\hline \multirow{10}{*}{$\begin{array}{l}\text { Number of previous abor- } \\
\text { tions on obstetric history }\end{array}$} & - Case group total & 0.33 & 0.69 & \multirow[t]{10}{*}{0.24} & \multirow[t]{10}{*}{0.60} & 0.015 \\
\hline & - Depression & 0.47 & 0.75 & & & 0.001 \\
\hline & - Epilepsy & 0.38 & 0.91 & & & 0.054 \\
\hline & - Substance abuse/dependence & 0 & 0 & & & 0.967 \\
\hline & $\begin{array}{l}\text { - Depression without } \\
\text { antidepressants }\end{array}$ & 0.51 & 0.83 & & & 0.002 \\
\hline & $\begin{array}{l}\text { - Depression with } \\
\text { antidepressants }\end{array}$ & 0.40 & 0.62 & & & 0.139 \\
\hline & - Epilepsy without AED & 0.33 & 0.49 & & & 0.313 \\
\hline & - Epilepsy with AED & 0.41 & 1.05 & & & 0.100 \\
\hline & $\begin{array}{l}\text { - Substance abuse without } \\
\text { substitution }\end{array}$ & 0 & 0 & & & 0.971 \\
\hline & $\begin{array}{l}\text { - Substance abuse with } \\
\text { substitution }\end{array}$ & 0 & 0 & & & 0.986 \\
\hline \multirow[t]{10}{*}{ Age } & - Case group total & 29.40 & 5.86 & \multirow[t]{10}{*}{29.67} & \multirow[t]{10}{*}{5.62} & 0.543 \\
\hline & - Depression & 31.23 & 4.93 & & & 0.043 \\
\hline & - Epilepsy & 28.87 & 6.29 & & & 0.765 \\
\hline & - Substance abuse & 24.83 & 5.89 & & & $<0.001$ \\
\hline & $\begin{array}{l}\text { - Depression without } \\
\text { antidepressants }\end{array}$ & 31.34 & 5.29 & & & 0.222 \\
\hline & $\begin{array}{l}\text { - Depression with } \\
\text { antidepressants }\end{array}$ & 31.07 & 4.38 & & & 0.675 \\
\hline & - Epilepsy without AED & 27.25 & 6.12 & & & 0.589 \\
\hline & - Epilepsy with AED & 29.59 & 6.34 & & & 1.000 \\
\hline & $\begin{array}{l}\text { - Substance abuse without } \\
\text { substitution }\end{array}$ & 24.11 & 5.88 & & & $<0.001$ \\
\hline & $\begin{array}{l}\text { - Substance abuse with } \\
\text { substitution }\end{array}$ & 28.25 & 5.32 & & & 0.997 \\
\hline \multirow[t]{10}{*}{ Number of antenatal visits } & - Case group total & 12.63 & 3.90 & \multirow[t]{10}{*}{12.05} & \multirow[t]{10}{*}{3.97} & 0.026 \\
\hline & - Depression & 13.75 & 3.94 & & & $<0.001$ \\
\hline & - Epilepsy & 11.45 & 3.29 & & & 0.323 \\
\hline & - Substance abuse & 10.70 & 3.64 & & & 0.198 \\
\hline & $\begin{array}{l}\text { - Depression without } \\
\text { antidepressants }\end{array}$ & 14.06 & 3.57 & & & $<0.001$ \\
\hline & $\begin{array}{l}\text { - Depression with } \\
\text { antidepressants }\end{array}$ & 13.21 & 4.51 & & & 0.112 \\
\hline & - Epilepsy without AED & 11.67 & 2.67 & & & 0.831 \\
\hline & - Epilepsy with AED & 11.35 & 3.59 & & & 0.294 \\
\hline & $\begin{array}{l}\text { Substance abuse without } \\
\text { substitution }\end{array}$ & 10.41 & 3.73 & & & 0.145 \\
\hline & $\begin{array}{l}\text { - Substance abuse with } \\
\text { substitution }\end{array}$ & 12.33 & 3.21 & & & 0.888 \\
\hline
\end{tabular}

$\mathrm{M}=$ mean, $\mathrm{SD}=$ standard deviation, $\mathrm{AED}=$ antiepileptic drug)

* Statistical significance testing with one-way analysis of variance for the criterion age, and generalised linear models with age as an additional covariable for the other criteria (for details see text section statistical analysis). The p values for the multiple group comparisons are derived from a Dunnett comparison between the subgroup and the control group in each case. 


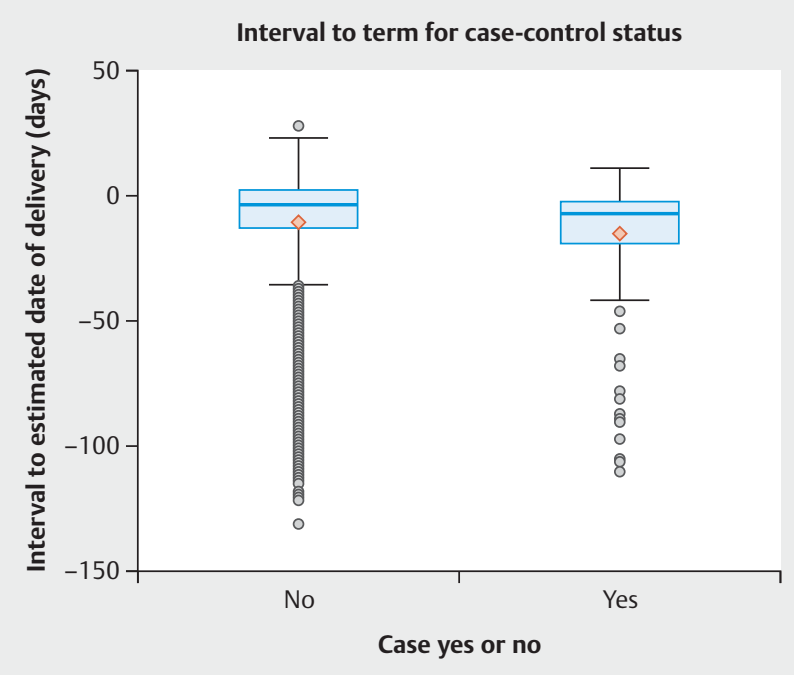

- Fig. 2 Box plot of interval to estimated date of delivery for case group and control group children. Y-axis: interval to EDD in days, $0=\operatorname{EDD}(40 / 0$ SSW $)$.

Birth weight in $\mathrm{g}$, length in $\mathrm{cm}$ and head circumference in cm

- Table 4: On average, and taking gestational age into account, children of case group mothers were not significantly lighter (SGA) or heavier (LGA) than children of control group mothers, nor did they have significantly smaller head circumferences $(p=0.378, p=0.916)$. Case group children were however significantly smaller in terms of birth length than control group children $(p=0.013)$.

On subgroup analysis significant differences between control group children and children of mothers with substance abuse were found for each of the parameters birth weight, length and head circumference. These differences were particularly significant for children of women with substance abuse without substitution therapy.

Also, children of women with depression and children of women on antidepressants had significantly larger head circumferences than control group children $(p=0.012, p<0.001)$.

\section{Apgar scores}

There were no significant differences in Apgar scores at 1, 5 and 10 minutes between children of case group mothers compared to controls. Only children whose mothers had epilepsy were treated with antiepileptic drugs showed significantly lower 1 minute Apgar scores ( $p=0.035)$.

- Table 4 provides an overview of the characteristics of case group and control group children.

\section{Discussion}

The prevalence of major depression among American pregnant women has been estimated at $12.4 \%$ [12]. The prevalence of general depressive symptoms among pregnant women is as high as $18.4 \%$ and in combination with anxiety disorders between 4.4 and $39 \%$ [13]. In industrialised countries rates of antenatal depression are between 7-15\% [14]. In our study collective the prevalence of depression and anxiety disorders was $1.5 \%$, which is relatively low compared to the above-mentioned studies.

The prevalence of epilepsy in the study collective (0.8\%) was similar to that in a German study from 2016 [11]. An American study also showed similar epilepsy prevalence (0.3-0.5\%) [15].

According to data from the American "National Survey on Drug Use and Health (NSDUH)" from 2012 the prevalence of illegal drug use during pregnancy was 5.9\% among American women [6]. Data from central Germany show a prevalence of substance abuse among pregnant women of only $0.7 \%$ [11]. In our singlecentre cohort the prevalence of substance abuse was comparable at $0.5 \%$. These differences in prevalence between American and central German data presumably reflect population differences as well as differences in antenatal care provision between the two countries.

Limited data have been published on pregnancy and neonatal outcomes in relation to maternal mental health in Germany. In this study we were able to analyse 5092 pregnancies in terms of maternal disease and disease-specific medication. Parameter documentation occurred during routine clinical care with data collection starting prospectively at first presentation to the maternity unit and being completed at delivery. Cases and controls were recruited from the same basis population (central Germany) and thus represent an homogenous cohort.

- Table 3 Overview of maternal results part 2.

\begin{tabular}{|l|l|l|l|}
\hline & & \multicolumn{1}{c|}{$\begin{array}{c}\text { Case group } \\
\text { (\%) }\end{array}$} & $\begin{array}{l}\text { Control group } \\
\text { (\%) }\end{array}$ \\
\hline \multirow{2}{*}{ Mode of delivery value) }
\end{tabular}


- Table 4 Overview of results for neonatal parameters.

\begin{tabular}{|c|c|c|c|c|c|c|}
\hline & & \multicolumn{2}{|c|}{ Case groups } & \multicolumn{2}{|c|}{ Control groups } & \multirow{2}{*}{ 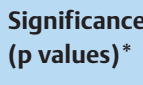 } \\
\hline & & M & SD & M & SD & \\
\hline \multirow{10}{*}{$\begin{array}{l}\text { Interval to EDD } \\
\text { in days }\end{array}$} & - Case group total & -14.84 & 22.55 & \multirow[t]{10}{*}{-10.43} & \multirow[t]{10}{*}{21.65} & 0.003 \\
\hline & - Depression & -12.51 & 20.27 & & & 0.739 \\
\hline & - Epilepsy & -12.20 & 18.75 & & & 0.830 \\
\hline & - Substance abuse/dependence & -16.77 & 24.70 & & & 0.155 \\
\hline & - Depression without antidepressants & -13.84 & 19,78 & & & 0.971 \\
\hline & - Depression with antidepressants & -10.30 & 21.22 & & & 0.996 \\
\hline & - Epilepsy without AED & -11.00 & 12.56 & & & 1.000 \\
\hline & - Epilepsy with AED & -12.78 & 21.29 & & & 0.841 \\
\hline & - Substance abuse without substitution & -17.61 & 27.06 & & & 0.293 \\
\hline & - Substance abuse with substitution & -13.00 & 9.90 & & & 0.998 \\
\hline \multirow{10}{*}{$\begin{array}{l}\text { Birth weight } \\
\text { in } \mathrm{g}\end{array}$} & - Case group total & 3013.77 & 768.37 & \multirow[t]{10}{*}{3162.96} & \multirow[t]{10}{*}{780.09} & 0.378 \\
\hline & - Depression & 3120.75 & 680.52 & & & 0.993 \\
\hline & - Epilepsy & 3106.50 & 719.56 & & & 0.987 \\
\hline & - Substance abuse & 2738.48 & 857.73 & & & 0.022 \\
\hline & - Depression without antidepressants & 3116.40 & 728.15 & & & 0.945 \\
\hline & - Depression with antidepressants & 3128.00 & 604.67 & & & 0.977 \\
\hline & - Epilepsy without AED & 2952.69 & 610.50 & & & 0.594 \\
\hline & - Epilepsy with AED & 3180.56 & 766.23 & & & 0.987 \\
\hline & - Substance abuse without substitution & 2698.42 & 870.44 & & & 0.049 \\
\hline & - Substance abuse with substitution & 2928.75 & 889.22 & & & 0.984 \\
\hline \multirow{10}{*}{$\begin{array}{l}\text { Birth length } \\
\text { in } \mathrm{cm}\end{array}$} & - Case group total & 49.26 & 4.58 & \multirow[t]{10}{*}{50.85} & \multirow[t]{10}{*}{2.95} & 0.013 \\
\hline & - Depression & 49.93 & 3.71 & & & 0.997 \\
\hline & - Epilepsy & 50.00 & 3.93 & & & 0.940 \\
\hline & - Substance abuse & 47.70 & 4.98 & & & $<0.001$ \\
\hline & - Depression without antidepressants & 50.06 & 3.87 & & & 0.950 \\
\hline & - Depression with antidepressants & 49.71 & 3.45 & & & 0.635 \\
\hline & - Epilepsy without AED & 50.25 & 2.56 & & & 0.997 \\
\hline & - Epilepsy with AED & 49.89 & 4.45 & & & 1.000 \\
\hline & - Substance abuse without substitution & 47.42 & 5.25 & & & $<0.001$ \\
\hline & - Substance abuse with substitution & 49.00 & 3.65 & & & 0.979 \\
\hline \multirow{10}{*}{$\begin{array}{l}\text { Head circum- } \\
\text { ference in cm }\end{array}$} & - Case group total & 33.75 & 5.54 & \multirow[t]{10}{*}{34.40} & \multirow[t]{10}{*}{1.74} & 0.916 \\
\hline & - Depression & 34.53 & 7.71 & & & 0.012 \\
\hline & - Epilepsy & 33.87 & 2.60 & & & 0.916 \\
\hline & - Substance abuse & 32.17 & 3.10 & & & $<0.001$ \\
\hline & - Depression without antidepressants & 33.64 & 2.62 & & & 0.962 \\
\hline & - Depression with antidepressants & 36.05 & 12.24 & & & $<0.001$ \\
\hline & - Epilepsy without AED & 34.00 & 1.45 & & & 0.995 \\
\hline & - Epilepsy with AED & 33.81 & 2.99 & & & 1.000 \\
\hline & - Substance abuse without substitution & 31.97 & 3.32 & & & $<0.001$ \\
\hline & - Substance abuse with substitution & 33.13 & 1.75 & & & 0.975 \\
\hline
\end{tabular}


- Table 4 Overview of results for neonatal parameters. (Continued)

\begin{tabular}{|c|c|c|c|c|c|c|}
\hline & & \multicolumn{2}{|c|}{ Case groups } & \multicolumn{2}{|c|}{ Control groups } & \multirow{2}{*}{$\begin{array}{l}\text { Significance } \\
\text { (p values) }^{*}\end{array}$} \\
\hline & & $\mathbf{M}$ & SD & $\mathbf{M}$ & SD & \\
\hline \multirow{10}{*}{$\begin{array}{l}\text { Apgar score } \\
\text { at } 1 \mathrm{~min}\end{array}$} & - Case group total & 8.63 & 1.38 & \multirow[t]{10}{*}{8.79} & \multirow[t]{10}{*}{1.37} & 0.765 \\
\hline & - Depression & 8.76 & 1.33 & & & 0.987 \\
\hline & - Epilepsy & 8.30 & 1.77 & & & 0.076 \\
\hline & - Substance abuse & 8.70 & 1.11 & & & 0.996 \\
\hline & - Depression without antidepressants & 8.88 & 1.17 & & & 0.820 \\
\hline & - Depression with antidepressants & 8.57 & 1.57 & & & 0.895 \\
\hline & - Epilepsy without AED & 8.77 & 0.83 & & & 1.000 \\
\hline & - Epilepsy with AED & 8.07 & 2.06 & & & 0.035 \\
\hline & - Substance abuse without substitution & 8.63 & 1.17 & & & 1.000 \\
\hline & - Substance abuse with substitution & 9.00 & 0.82 & & & 0.998 \\
\hline \multirow{10}{*}{$\begin{array}{l}\text { Apgar score } \\
\text { at } 5 \text { min }\end{array}$} & - Case group total & 9.40 & 1.01 & \multirow[t]{10}{*}{9.50} & \multirow[t]{10}{*}{1.03} & 0.940 \\
\hline & - Depression & 9.51 & 0.89 & & & 0.891 \\
\hline & - Epilepsy & 9.25 & 1.24 & & & 0.386 \\
\hline & - Substance abuse & 9.30 & 1.02 & & & 0.974 \\
\hline & - Depression without antidepressants & 9.58 & 0.84 & & & 0.725 \\
\hline & - Depression with antidepressants & 9.40 & 0.97 & & & 0.989 \\
\hline & - Epilepsy without AED & 9.46 & 0.66 & & & 1.000 \\
\hline & - Epilepsy with AED & 9.15 & 1.43 & & & 0.413 \\
\hline & - Substance abuse without substitution & 9.21 & 1.08 & & & 0.976 \\
\hline & - Substance abuse with substitution & 9.75 & 0.50 & & & 0.985 \\
\hline \multirow{10}{*}{$\begin{array}{l}\text { Apgar score } \\
\text { at } 10 \mathrm{~min}\end{array}$} & - Case group total & 9.68 & 0.69 & \multirow[t]{10}{*}{9.75} & \multirow[t]{10}{*}{0.78} & 0.796 \\
\hline & - Depression & 9.70 & 0.70 & & & 0.999 \\
\hline & - Epilepsy & 9.70 & 0.65 & & & 0.999 \\
\hline & - Substance abuse & 9.61 & 0.84 & & & 0.996 \\
\hline & - Depression without antidepressants & 9.74 & 0.72 & & & 0.997 \\
\hline & - Depression with antidepressants & 9.63 & 0.67 & & & 0.949 \\
\hline & - Epilepsy without AED & 9.85 & 0.38 & & & 0.995 \\
\hline & - Epilepsy with AED & 9.63 & 0.74 & & & 0.997 \\
\hline & - Substance abuse without substitution & 9.53 & 0.91 & & & 0.988 \\
\hline & - Substance abuse with substitution & 10.00 & 0.00 & & & 0.945 \\
\hline
\end{tabular}

This study shows an increased number of previous abortions on obstetric history among women with neuropsychiatric illnesses. Women with depression were most affected. A study from 2015 found correlation between recurrent abortions, increased prevalence of depression and high levels of emotional stress [16]. Another study showed that the risk of abortion (maternal age 2529 years) increased from $8.9-9.3 \%$ in women without previous abortions on obstetric history, to $11.8-12.4 \%$ in women with one previous abortion, and to 17.7 to $22.7 \%$ with two previous abortions. Thus women with neuropsychiatric illness also had an increased risk of future abortions (due to higher numbers of previous abortions) [17].
It is notable in this study that, when medication is taken into account, abortion risk was significantly increased in women with depression who were not taking antidepressants. In contrast risk of abortion was not significantly increased among women with depression who were taking antidepressants. Increased risk of abortion therefore does not primarily appear to be a toxic effect of medication; rather "depression" itself is a risk factor for recurrent abortion. This conclusion has also been reached in relation to use of duloxetine (SSNRI = selective serotonin noradrenaline reuptake inhibitor) during pregnancy. In this study the authors found that the risk of fatal pregnancy outcomes (spontaneous abortion, premature birth) was not increased in women taking duloxetine 
[18]. Studies of the use of SSRIs (fluvoxamine, paroxetine, sertraline, escitalopram) in pregnancy have also not shown any increased risk of spontaneous abortion $[19,20]$.

One study from 2014 however showed controversial results contradictory to those above, finding a one to three times increased relative risk of spontaneous abortion for the use of duloxetine during pregnancy [21].

Analysis of our data confirms the focus on depression as the relevant risk factor. Women with depression were significantly older than controls so that age may be a possible cofactor. One study has shown that the risk of spontaneous abortion increases from $8.7 \%$ at the age of 22 to $84.1 \%$ at the age of 48 years $[17,22,23]$.

In our study spontaneous vaginal delivery was the most common mode of delivery in both the case and control groups, however approximately $10 \%$ fewer women in the case group delivered spontaneously ( $C G=53.4 \%$; $C o G=64.8 \%$ ). The proportion of caesarean sections overall was $44 \%$ in the case group and only $32.4 \%$ in the control group, i.e. $10 \%$ more women in the case group had caesarean sections than in the control group. An increased caesarean section rate has been described in women with bipolar disorder $(23.5 \%)$ compared to women without bipolar disorder $(16.8 \%)[24,25,26]$. Interestingly, in the case group more planned, primary caesareans (18.3\%) than secondary caesarean sections (14.7\%) were performed, which may have been due to existing maternal illness. The opposite was true in the control group (primary caesarean $=11.9 \%$, secondary caesarean $=$ $12.6 \%$, the decision to perform caesarean section more commonly being made after labour had commenced, due to unpredictable (in contrast to primary caesarean), often fetal birth complications. The remaining numbers were made up by operative vaginal deliveries (forceps, vacuum extraction).

Our data also show a significant difference in the interval between birth and estimated date of delivery between children of case group and control group mothers. Children of women with neuropsychiatric illness were born on average 14.84 days before their EDD while control group children were born 10.43 days before EDD. A meta-analysis from 2013 also showed a relationship between women with medically treated depression and birth before EDD [27].

Common to both groups in this case-control study was that although births occurred early, they did not reach prematurity ( $\geq 37 / 0$ weeks of gestation). In contrast, a study from 2014 found that children of schizophrenic women were at increased risk of premature birth. Increased risk of prematurity has also been shown in studies of women with post-traumatic stress disorder, anxiety disorders, depression and heroin consumption [10,28, 29].

A possible reason for children in our data analysis on average not being born prematurely is that there were more women in the case group not on medical treatment than women taking medication. Numerous studies have shown that, amongst other medications, antidepressants may increase the risk of premature birth, and that the risk of prematurity increases with increasing severity of depression [30,31]. Since the majority of women in our case group were not on antidepressants we presume that their depression was milder, and therefore the risk of prematurity lower.

In contrast to gestational age at birth there was no significant difference for average birth weight or head circumference between cases and controls, taking gestational age into account. There was also no significant difference between the groups on comparison of Apgar scores at 1, 5 and 10 minutes. Although children of case group mothers were an average of $82.2 \mathrm{~g}$ lighter than control children, producing a trend, this is more likely attributable to shorter gestations than to the maternal illnesses themselves.

Only the children of women with substance abuse and especially those without substitution therapy had significantly lower birth weight and smaller length and head circumference measurements, a finding consistent with other studies [32,33].

The meta-analysis by Ross et al. provides contrasting results: children whose mothers had depression were significantly lighter and had lower Apgar scores than children of mothers without medically treated neuropsychiatric illness [27]. Other studies have also shown that newborns of women with neuropsychiatric illness are at increased risk of low birth weight $[11,34]$. This difference can also be explained by the greater proportion of control group women in this study without medication than with medication, since according to study data neuropsychiatric medication in particular can result in low birth weight $[35,36]$.

Large meta-analyses of maternal epilepsy, depression and anxiety disorders have identified the disorders themselves as risk factors for abortion, prematurity and intrauterine growth retardation independent of disease-specific medication [37-39]. The influence of cofactors such as tobacco smoking, alcohol consumption and illicit drug use is controversial $[40,41]$.

Data for this study were collected continuously over a period of 3.25 years by specialised staff at a single institution irrespective of case or control group allocation. Nevertheless on critical review "recall error" is possible among these mothers with addiction or neuropsychiatric illness. In order to minimise this error maternal and neonatal data were also collected from postnatal documentation by doctors and nurses as well as medical and midwifery documentation of antenatal visits. For the parameter "mode of delivery" cases in the subgroup "other caesarean sections" could not be allocated to either of the subgroups "primary classical caesarean" or "secondary caesarean". Practice relevant findings may have resulted if allocation to these groups had been possible, however incomplete and implausible data had to be excluded from the analysis.

\section{Conclusion for Clinical Practice}

This study provides evidence that women with neuropsychiatric illnesses are at increased risk of having an abortion.

The data also suggest that antidepressants themselves are not solely responsible for this increased risk.

The rate of caesarean section is increased by $10 \%$ in the context of maternal neuropsychiatric illness and substance abuse.

Children of mothers with neuropsychiatric illnesses are born at younger gestational ages. These newborns however do not have worse perinatal outcomes: birth is generally not preterm, and parameters such as birth weight, head circumference and Apgar 
scores are comparable with newborns of mentally healthy women.

This study underscores the significance of maternal neuropsychiatric health for pregnancy outcomes and highlights the need for specialised antenatal care of affected women.

\section{Conflict of Interest}

The authors declare that they have no conflict of interest.

\section{References}

[1] Ruscio AM, Hallion LS, Lim CCW et al. Cross-sectional comparison of the epidemiology of DSM- 5 generalized anxiety disorder across the globe. JAMA Psychiatry 2017; 74: 465-475

[2] Busch MA, Maske UE, Ryl L et al. Prävalenz von depressiver Symptomatik und diagnostizierter Depression bei Erwachsenen in Deutschland: Ergebnisse der Studie zur Gesundheit Erwachsener in Deutschland (DEGS1). Bundesgesundheitsblatt, Gesundheitsforschung, Gesundheitsschutz 2013; 56: 733-739

[3] Murray CJL, Lopez AD. Alternative projections of mortality and disability by cause 1990-2020. Global Burden of Disease Study. Lancet 1997; 349: 1498-1504

[4] Jacobi F, Hofler M, Siegert J et al. Twelve-month prevalence, comorbidity and correlates of mental disorders in Germany: the Mental Health Module of the German Health Interview and Examination Survey for Adults (DEGS1-MH). Int J Methods Psychiatr Res 2014; 23: 304-319

[5] Hand D], Short VL, Abatemarco DJ. Treatments for opioid use disorder among pregnant and reproductive-aged women. Fertil Steril 2017; 108: $222-227$

[6] Gopman S. Prenatal and postpartum care of women with substance use disorders. Obstet Gynecol Clin North Am 2014; 41: 213-228

[7] Keegan J, Parva M, Finnegan M et al. Addiction in pregnancy. J Addict Dis 2010; 29: 175-191

[8] Reis M, Kallen B. Delivery outcome after maternal use of antidepressant drugs in pregnancy: an update using Swedish data. Psychol Med 2010; 40: $1723-1733$

[9] Lennestal R, Kallen B. Delivery outcome in relation to maternal use of some recently introduced antidepressants. J Clin Psychopharmacol 2007; 27: 607-613

[10] Vigod SN, Kurdyak PA, Dennis CL et al. Maternal and newborn outcomes among women with schizophrenia: a retrospective population-based cohort study. BJOG 2014; 121: 566-574

[11] Grunwald L, Jorch G, Kropf S et al. Die Bedeutung neurologischer, psychiatrischer und Suchterkrankungen für den Schwangerschaftsausgang: Fall-Kontroll-Studie der Geburtsjahrgänge 2010-2012. Zeitschrift für Geburtshilfe und Neonatologie 2016; 220: 116-123

[12] Le Strat Y, Dubertret C, Le Foll B. Prevalence and correlates of major depressive episode in pregnant and postpartum women in the United States. J Affect Disord 2011; 135: 128-138

[13] Ulrich F, Petermann F. Consequences and possible predictors of healthdamaging behaviors and mental health problems in pregnancy - a review. Geburtsh Frauenheilk 2016; 76: 1136-1156

[14] Gelaye B, Rondon MB, Araya R et al. Epidemiology of maternal depression, risk factors, and child outcomes in low-income and middle-income countries. Lancet Psychiatry 2016; 3: 973-982
[15] Harden CL, Hopp J, Ting TY et al. Practice parameter update: management issues for women with epilepsy-focus on pregnancy (an evidence-based review): obstetrical complications and change in seizure frequency: report of the Quality Standards Subcommittee and Therapeutics and Technology Assessment Subcommittee of the American Academy of Neurology and American Epilepsy Society. Neurology 2009; 73: 126-132

[16] Kolte AM, Olsen LR, Mikkelsen EM et al. Depression and emotional stress is highly prevalent among women with recurrent pregnancy loss. Hum Reprod 2015; 30: 777-782

[17] Nybo Andersen AM, Wohlfahrt J, Christens P et al. Maternal age and feta loss: population based register linkage study. BMJ 2000; 320: 17081712

[18] Hoog SL, Cheng Y, Elpers J et al. Duloxetine and pregnancy outcomes: safety surveillance findings. Int J Med Sci 2013; 10: 413-419

[19] Kulin NA, Pastuszak A, Sage SR et al. Pregnancy outcome following maternal use of the new selective serotonin reuptake inhibitors: a prospective controlled multicenter study. JAMA 1998; 279: 609-610

[20] Bellantuono C, Orsolini L, Bozzi F. La sicurezza dell'escitalopram in gravidanza e nell'allattamento. Riv Psichiatr 2013; 48: 407-414

[21] Andrade C. The safety of duloxetine during pregnancy and lactation. J Clin Psychiatry 2014; 75: e1423-e1427

[22] Zhang D, Shi W, Li C et al. Risk factors for recurrent ectopic pregnancy: a case-control study. BJOG 2016; 123 (Suppl. 3): 82-89

[23] Muller V, Makhmadalieva M, Kogan I et al. Ectopic pregnancy following in vitro fertilization: meta-analysis and single-center experience during 6 years. Gynecol Endocrinol 2016; 32 (Suppl. 2): 69-74

[24] Spain J, Rheinboldt M. MDCT of pelvic inflammatory disease: a review of the pathophysiology, gamut of imaging findings, and treatment. Emerg Radiol 2017; 24: 87-93

[25] Reddy UM, Davis JM, Ren Z et al. Opioid use in pregnancy, neonatal abstinence syndrome, and childhood outcomes: executive summary of a joint workshop by the Eunice Kennedy Shriver National Institute of Child Health and Human Development, American College of Obstetricians and Gynecologists, American Academy of Pediatrics, Society for MaternalFetal Medicine, Centers for Disease Control and Prevention, and the March of Dimes Foundation. Obstet Gynecol 2017; 130: 10-28

[26] Rusner M, Berg M, Begley C. Bipolar disorder in pregnancy and childbirth: a systematic review of outcomes. BMC Pregnancy Childbirth 2016; 16: 331

[27] Ross LE, Grigoriadis S, Mamisashvili L et al. Selected pregnancy and delivery outcomes after exposure to antidepressant medication: a systematic review and meta-analysis. JAMA Psychiatry 2013; 70: 436-443

[28] Hoirisch-Clapauch S, Brenner B, Nardi AE. Adverse obstetric and neonatal outcomes in women with mental disorders. Thromb Res 2015; 135: 60-63

[29] Bennett AD. Perinatal substance abuse and the drug-exposed neonate. Adv Nurse Pract 1999; 7: 32-36; quiz 37-38

[30] Li D, Liu L, Odouli R. Presence of depressive symptoms during early pregnancy and the risk of preterm delivery: a prospective cohort study. Hum Reprod 2009; 24: 146-153

[31] Field T. Prenatal depression effects on early development: a review. Infant Behav Dev 2011; 34: 1-14

[32] Chiriboga CA. Fetal alcohol and drug effects. Neurologist 2003; 9: 267279

[33] Covington CY, Nordstrom-Klee B, Ager J et al. Birth to age 7 growth of children prenatally exposed to drugs: a prospective cohort study. Neurotoxicol Teratol 2002; 24: 489-496

[34] Pinto TM, Caldas F, Nogueira-Silva $C$ et al. Maternal depression and anxiety and fetal-neonatal growth. J Pediatr (Rio J) 2017; 93: 452-459 
[35] Sutter-Dallay AL, Bales M, Pambrun E et al. Impact of prenatal exposure to psychotropic drugs on neonatal outcome in infants of mothers with serious psychiatric illnesses. J Clin Psychiatry 2015; 76: 967-973

[36] Diego MA, Field T, Hernandez-Reif $M$ et al. Prenatal depression restricts fetal growth. Early Hum Dev 2009; 85: 65-70

[37] Viale L, Allotey J, Cheong-See F et al. Epilepsy in pregnancy and reproductive outcomes: a systematic review and meta-analysis. Lancet 2015; 386: 1845-1852

[38] Hollins K. Consequences of antenatal mental health problems for child health and development. Curr Opin Obstet Gynecol 2007; 19: 568-572
[39] Addis A, Moretti ME, Ahmed Syed F et al. Fetal effects of cocaine: an updated meta-analysis. Reprod Toxicol 2001; 15: 341-369

[40] van Tong T, Farr SL, Bombard J et al. Smoking before and during pregnancy among women reporting depression or anxiety. Obstet Gynecol 2016; 128: 562-570

[41] Cantarutti A, Merlino L, Monzani E et al. Is the risk of preterm birth and low birth weight affected by the use of antidepressant agents during pregnancy? A population-based investigation. PLoS One 2016; 11: e0168115 